\title{
Influence of the Cr5+ ion on the magnetic properties of YbCrO4 oxide
}

DOI:

10.1016/j.jmmm.2003.11.216

\section{Document Version}

Final published version

Link to publication record in Manchester Research Explorer

\section{Citation for published version (APA):}

Jimenez-Melero, E., Bonville, P., Hodges, J. A., Gubbens, P. C. M., Isasi, J., \& Saez-Puche, R. (2004). Influence of the $\mathrm{Cr} 5+$ ion on the magnetic properties of $\mathrm{YbCrO} 4$ oxide. Journal of Magnetism and Magnetic Materials, 272-276(1), 571-573. https://doi.org/10.1016/j.jmmm.2003.11.216

\section{Published in:}

Journal of Magnetism and Magnetic Materials

\section{Citing this paper}

Please note that where the full-text provided on Manchester Research Explorer is the Author Accepted Manuscript or Proof version this may differ from the final Published version. If citing, it is advised that you check and use the publisher's definitive version.

\section{General rights}

Copyright and moral rights for the publications made accessible in the Research Explorer are retained by the authors and/or other copyright owners and it is a condition of accessing publications that users recognise and abide by the legal requirements associated with these rights.

\section{Takedown policy}

If you believe that this document breaches copyright please refer to the University of Manchester's Takedown Procedures [http://man.ac.uk/04Y6Bo] or contact uml.scholarlycommunications@manchester.ac.uk providing relevant details, so we can investigate your claim.

\section{OPEN ACCESS}




\title{
Influence of the $\mathrm{Cr}^{5+}$ ion on the magnetic properties of $\mathrm{YbCrO}_{4}$ oxide
}

\author{
E. Jimenez ${ }^{\mathrm{a}, *}$, P. Bonville ${ }^{\mathrm{b}}$, J.A. Hodges ${ }^{\mathrm{b}}$, P.C.M. Gubbens ${ }^{\mathrm{c}}$, \\ J. Isasi ${ }^{\mathrm{a}}, \mathrm{R}$. Saez-Puche ${ }^{\mathrm{a}}$ \\ ${ }^{a}$ Dpto. Q. Inorganica, Fac. C. Quimicas, Universidad Complutense de Madrid, Ciudad Universitaria, 28040-Madrid, Spain \\ ${ }^{\mathrm{b}}$ CEA Saclay, DSMIDRECAM, Service de Physique de l'Etat Condensé, 91191 Gif-sur-Yvette, France \\ ${ }^{\mathrm{c}}$ Interfacultair Reactor Instituut, TUDelft, Mekelweg 15, $2629 \mathrm{JB}$-Delft, The Netherlands
}

\begin{abstract}
The magnetic properties of the $\mathrm{YbCrO}_{4}$ oxide have been studied by both bulk magnetic measurements and ${ }^{170} \mathrm{Yb}$ Mössbauer spectroscopy. Ferrimagnetic ordering is shown to be present below $25 \mathrm{~K}$, driven by the exchange within the chromium sublattice. In the saturation state, the magnetic moment is $0.55 \mu_{\mathrm{B}}$ for $\mathrm{Yb}^{3+}$, and presumably $1 \mu_{\mathrm{B}}$ for $\mathrm{Cr}^{5+}$, the two sublattices being antiferromagnetically coupled. The anisotropic $\mathrm{Yb}-\mathrm{Cr}$ exchange polarises the $\mathrm{Yb}^{3+}$ sublattice below $25 \mathrm{~K}$, so as to force the $\mathrm{Yb}$ magnetic moments to lie in the hard magnetic $a-b$ plane.
\end{abstract}

(C) 2004 Elsevier B.V. All rights reserved.

PACS: $75.50 . \mathrm{Gg} ; 76.30 . \mathrm{Kg}$

Keywords: $\mathrm{YbCrO}_{4}$; Zircon-type structure; Magnetic ordering; Mössbauer spectroscopy

Rare earth chromates constitute a subgroup of the family of compounds of general formula $\mathrm{RXO}_{4}$, where $\mathrm{R}(\mathrm{III})=$ rare earth, while $\mathrm{X}(\mathrm{V})$ symbolises the following ions: $\mathrm{V}(\mathrm{V}), \mathrm{As}(\mathrm{V}), \mathrm{P}(\mathrm{V})$ and $\mathrm{Cr}(\mathrm{V})$ [1]. Few studies have been performed so far in the mentioned chromates [2]. We have focused on the magnetic properties of the zircon-type $\mathrm{YbCrO}_{4}$ oxide. Basing on the existing studies on the isomorphic $\mathrm{YbVO}_{4}, \mathrm{YbAsO}_{4}$ and $\mathrm{YbPO}_{4}$ compounds, the influence of the $\mathrm{Cr}^{5+}$ ion on the overall magnetic properties of the $\mathrm{YbCrO}_{4}$ can be thoroughly assessed.

In a first stage, we measured the magnetic susceptibility of the sample as a function of temperature to determine its magnetic ordering temperature, turning out to be $25 \mathrm{~K}$. Subsequently, the magnetisation was recorded as a function of the external magnetic field up to $1 \mathrm{~T}$ at different temperatures. Fig. 1 collects the data corresponding to 35 and $20 \mathrm{~K}$. While the magnetisation varies linearly with the magnetic field at $35 \mathrm{~K}$, a

\footnotetext{
*Corresponding author. Tel.: + 34-91-3944353; fax: +34-913944352.

E-mail address: ejmelero@quim.ucm.es (E. Jimenez).
}

hysteresis loop has been obtained at $20 \mathrm{~K}$. This fact confirms the previously obtained value for the magnetic ordering temperature, as well as the presence of ferro- or ferrimagnetic interactions in the $\mathrm{YbCrO}_{4}$ oxide. Both the remanence and the coercivity field increases with decreasing temperature, from $0.4 \mu_{\mathrm{B}}$ and $675 \mathrm{Oe}$ at $20 \mathrm{~K}$ to $0.55 \mu_{\mathrm{B}}$ and $3250 \mathrm{Oe}$ at $2 \mathrm{~K}$, respectively.

The Mössbauer spectra on the ${ }^{170} \mathrm{Yb}$ isotope were measured between 4.2 and $30 \mathrm{~K}$. Some selected spectra are represented in Fig. 2. An extra absorption has been detected near the centre of the spectrum coming from an impurity phase, the $\mathrm{Yb}_{2} \mathrm{O}_{3}$ oxide, whose known spectrum has been included in Fig. 2 as a dashed line. Its substantially high Debye temperature, when compared with the one corresponding to the $\mathrm{YbCrO}_{4}$ compound, can probably be the cause for its seemingly large Mössbauer percentage, which amounts to $35(10) \%$.

The $\mathrm{YbCrO}_{4}$ Mössbauer spectra comprise only a quadrupolar contribution between 25 and $30 \mathrm{~K}$, with a quadrupolar coupling constant: $\alpha_{\mathrm{Q}}=3.5 \mathrm{~mm} / \mathrm{s}$. Below $25 \mathrm{~K}$, a mixed magnetic-quadrupolar hyperfine pattern is clearly present, thus supporting the previously 


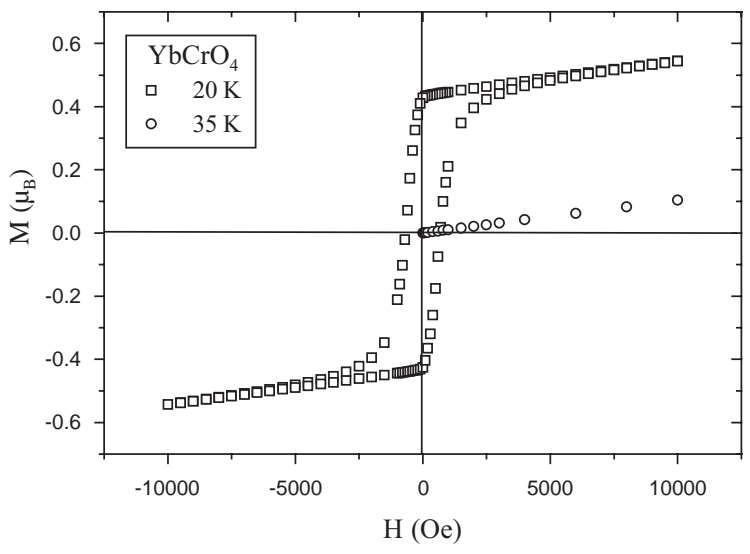

Fig. 1. Variation of the $\mathrm{YbCrO}_{4}$ magnetisation with the external magnetic field at 20 and $35 \mathrm{~K}$.

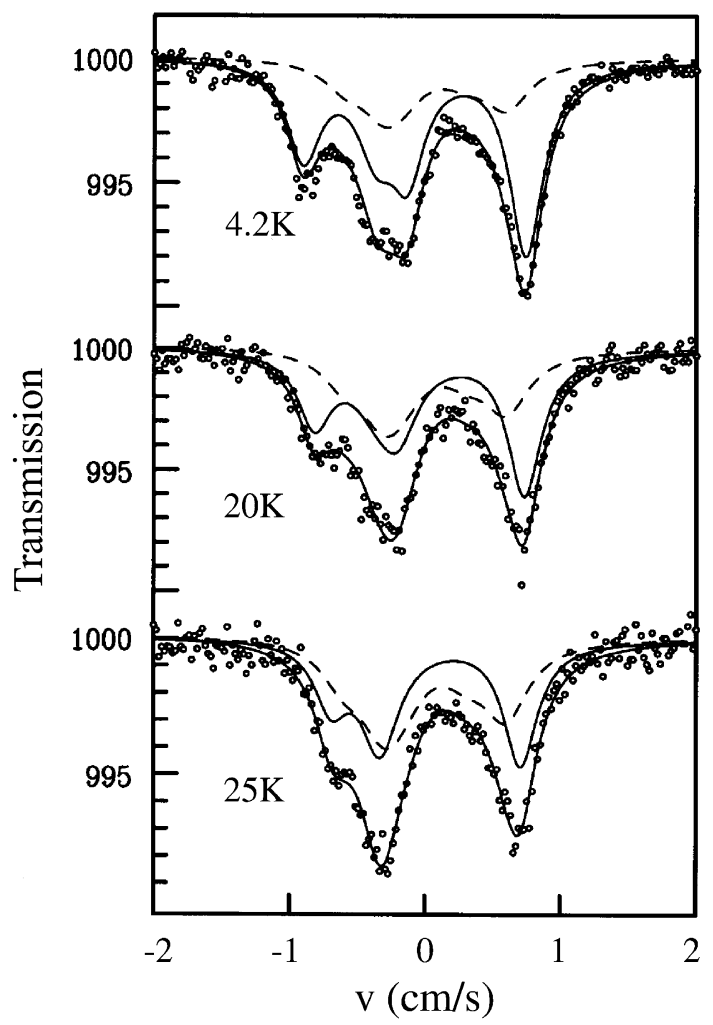

Fig. 2. ${ }^{170} \mathrm{Yb}$ Mössbauer absorption spectra of the $\mathrm{YbCrO}_{4}$ oxide. The dashed line represents the spectrum of the impurity phase $\mathrm{Yb}_{2} \mathrm{O}_{3}$.

determined ordering temperature. In local tetragonal symmetry $\left(\mathrm{D}_{2 \mathrm{~d}}\right.$ in this case), the principal axis (z-direction) of the electric field gradient tensor is along the four-fold symmetry axis, i.e. the crystallographic $c$ axis. The fitting procedure of the spectrum at $4.2 \mathrm{~K}$ yields a hyperfine field of $55 \mathrm{~T}$, corresponding to a saturated $\mathrm{Yb}$ magnetic moment of $m_{0}=0.55 \mu_{\mathrm{B}}$, which is significantly reduced with respect to the theoretical value of $g_{J} J=4 \mu_{\mathrm{B}}$. Moreover, the hyperfine field is perpendicular to the $c$-axis.

In the zircon-type $\mathrm{YbXO}_{4}$ compounds, an isolated Kramers doublet can be attributed to the crystal field ground state of the $\mathrm{Yb}^{3+}$ ion [3]. Such doublet can be described by an effective spin $\mathrm{S}=\frac{1}{2}$ and a spectroscopic $g$-tensor which, in the case of axial symmetry, has two components $g_{z}$ and $g_{\perp}$ defined by

$g_{z}=2 g_{j}\left|\left\langle\psi\left|J_{z}\right| \psi\right\rangle\right|$,

$g_{\perp}=2 g_{j}\left|\left\langle\psi\left|J_{x}\right| \psi^{\prime}\right\rangle\right|$,

where $|\psi\rangle$ and $\left|\psi^{\prime}\right\rangle$ are the Kramers conjugate states of the doublet. The $4 \mathrm{f}$ quadrupole coupling parameter is given by (if one neglects the usually small lattice charges contribution): $\alpha_{\mathrm{Q}}=B_{\mathrm{Q}}\left\langle\psi\left|3 J_{\mathrm{z}}^{2}-J(J+1)\right| \psi\right\rangle$, where $B_{\mathrm{Q}}=0.276 \mathrm{~mm} / \mathrm{s}$ for the ${ }^{170} \mathrm{Yb}^{3+}$ ion. In local tetragonal symmetry, the crystal field eigenfunctions can be mixtures of either the $|+5 / 2\rangle$ and $|-3 / 2\rangle$ states, or of the $|+7 / 2\rangle$ and $|-1 / 2\rangle$ states, where $|m\rangle$ stands for $\left|J=7 / 2 ; J_{z}=m\right\rangle$. From the measured values of $\alpha_{\mathrm{Q}}$ and $g_{\perp}=2 m_{0} / \mu_{\mathrm{B}}=1.1$ at $4.2 \mathrm{~K}$, the approximate wavefunction for the ground state is

$|\psi\rangle=0.87\left|J=\frac{7}{2} ; J_{z}=\frac{7}{2}\right\rangle+0.49\left|J=\frac{7}{2} ; J_{z}=-\frac{1}{2}\right\rangle$.

This wave-function, in turn, results in a value for the longitudinal component of the $g$-tensor of $g_{z}=5.8$. These values are relatively close to those obtained for the $\mathrm{Yb}^{3+}$ ion in $\mathrm{YbVO}_{4}: g_{z}=6.46$ and $g_{\perp}=0.77$, and in $\mathrm{YVO}_{4}: g_{z}=6.08$ and $g_{\perp}=0.85$ [4]. Surprisingly, in the magnetically ordered state, the $\mathrm{Yb}$ moments do not lie along the easy $c$-axis but in the $a-b$ plane, which constitutes a hard magnetic plane. Therefore, it must be concluded that the $\mathrm{Yb}-\mathrm{Cr}$ exchange imposes the direction of the $\mathrm{Yb}$ magnetic moments, i.e. it is anisotropic, the $\mathrm{Cr}^{5+}$ ion having an isotropic $g$-tensor.

We can now address the question of the nature of the $\mathrm{Yb}-\mathrm{Cr}$ coupling, i.e. whether it is ferro- or ferrimagnetic, basing on the measured remanence moment at $2 \mathrm{~K}$. The saturated moment of the $\mathrm{Cr}^{5+}$ ion is $2 S=1 \mu_{\mathrm{B}}$ (if no covalency effects are present in the $\mathrm{Cr}-\mathrm{O}$ bond), while that of the $\mathrm{Yb}^{3+}$ ion depends on the orientation of the magnetic field. For a polycrystalline sample, the saturated magnetisation of an extremely anisotropic doublet (i.e. $g_{\perp} / g_{z} \ll 1$ ) averaged over all orientations is $\frac{1}{4} g_{z} \mu_{\mathrm{B}}$. Using this result for $\mathrm{Yb}$ in $\mathrm{YbCrO}_{4}\left(g_{\perp} / g_{z} \approx 0.2\right)$, we obtain: $1.45 \mu_{\mathrm{B}}$. This implies that the experimental remanence moment at $2 \mathrm{~K}$, of $0.55 \mu_{\mathrm{B}}$ per formula unit, would correspond to a ferrimagnetic structure, the $\mathrm{Yb}-$ $\mathrm{Cr}$ coupling being antiferromagnetic.

Comparatively, the $\mathrm{YbVO}_{4}$ oxide displays a threedimensional antiferromagnetic ordering along the $c$-axis with a Néel temperature of $93 \mathrm{mK}$, and an ordered $\mathrm{Yb}^{3+}$ magnetic moment of $3.1 \mu_{\mathrm{B}}$ [5]. The remarkable differ- 
ence in the magnetic ordering temperature between the isostructural $\mathrm{YbCrO}_{4} \quad\left(T_{\mathrm{C}}=25 \mathrm{~K}\right)$ and $\mathrm{YbVO}_{4}$ $\left(T_{\mathrm{N}}=93 \mathrm{mK}\right)$ oxides, coupled with a different sign of the magnetic interactions and the alignment of the $\mathrm{Yb}^{3+}$ magnetic moments along the $a-b$ plane in the $\mathrm{YbCrO}_{4}$ oxide, points to the dominant role that the $\mathrm{Cr}^{5+}$ magnetic ion plays in determining the overall magnetic ordering temperature, as well as polarising the magnetic moments of the $\mathrm{Yb}^{3+}$ ions along a hard direction of magnetisation.

\section{References}

[1] H. Schwarz, Z. Anorg. Allg. Chem. 323 (1963) 44.

[2] H. Walter, H.G. Kahle, K. Mulder, H.C. Schopper, H. Schwarz, Int. J. Magn. 5 (1973) 129.

[3] Z.A. Kazei, N.P. Kolmakova, O.A. Shishkina, J. Exp. Theor. Phys. 93 (6) (2001) 1250

[4] G.J. Bowden, Aust. J. Phys. 51 (1998) 201 and references therein.

[5] P. Radhakrishna, J. Hammann, P. Pari, J. Magn. Magn. Mater. 23 (1981) 254. 